\title{
Permainan Ludo untuk Meningkatkan Keterampilan Kolaborasi Siswa dalam Pembelajaran Matematika
}

\author{
Mishbah Ulhusna ${ }^{1 *}$ Sri Diana Putri², Zakirman ${ }^{3}$ \\ ${ }_{12}$ Program studi teknik informatika, Fakultas ilmu computer, Universitas putra Indonesia, Padang, Indonesia \\ ${ }^{3}$ Program studi ilmu pendidikan, universitas Negeri Padang, Padang, Indonesia
}

\begin{abstract}
A R T I C L E I N F O Article history:

Received 18 March 2020

Received in revised form

30 April 2020

Accepted 5 May 2020

Available online 15 May 2020

Kata Kunci:

ludo, kolaborasi

matematika

Keywords:

ludo, colaboration,

matematic

A B S T R A K

Pelajaran matematika adalah salah satu mata pelajaran yang bagi sebagian orang adalah pelajaran yang sulit serta menakutkan. Adanya perasaan yang takut inilah menyebakan anak-anak merasa terpaksa belajar serta merasa tidak nyaman, secara tidak langsung hal ini memepengaruhi hasil belajar, alasan yang lain adalah kurangnya aktivitas dalam pembelajaran yang dapat melatih dan meningkatkan keterampilan kolaborasi siswa. Pembelajaran akan lebih bermakna apabila melibatkan teman sejawat sebagai salah satu unsur untuk membangun pengetahuan siswa. Oleh sebab itu tujuan dari penelitian ini adalah manganalisis dampak dari Permainan Ludo terhadap peningkatan Keterampilan Kolaborasi Siswa dalam Pembelajaran Matematika. Jenis penelitian ini adalah kuasi eksperimen dengan sampel sebanyak 21 orang siswa kelas III SDN 19 Nan Sabaris. Instrument pengumpulan data yang digunakan adalah lembar penilaian keterampilan kolaborasi siswa. Teknik analisis data dalam penelitian ini menggunakan uji efektivitas menggunakan persamaan uji kesamaan dua rata-rata (paired sample t-test). Hasil penelitian menunjukkan nilai sig. (2-tailed) sebesar 0.0000 lebih kecil dari nilai alfa (0.05), sehingga terdapat perbedaan keterampilan kolaborasi siswa yang signifikan antara siswa yang belajar menggunakan media ludo dan belajar secara konvensional. Dengan adanya penelitian ini akan memberikan kesemapatan kedapa guru untuk menginovasi pembelajaran dengan memadukan model pembelajaran dengan permainan ludo ataupun permainan tradisional lainya, yang nantinya bisa meningkatkan keterampilan kolaborasi siswa ataupun hasil belajar siswa.
\end{abstract}

\section{A B S T R A C T}

Mathematic is one of the difficult and scary subjects. Sometimes, the students feel afraid and it makes them feel forced and uncomfortable. Indirectly this situation would affect the students' learning outcomes and another reason was the lack of activities in learning mathematics which could train and enhance students' collaborative skill. Learning would be more meaningful if it involved peers to build students' knowledge. Therefore, the purpose of this research was to find out the effect of Ludo game in improving students' collaborative skill. This research was quasi-experimental with the sample of 21 students on third grade in SD 19 Nan Sabaris. The instrument used students' collaborative assessment sheet. The data analyzed by using effectiveness test with paired sample t-test. The conclusion showed that there were significant different on students' collaborative skill between the students who were taught by using Ludo and the students who were taught by using conventional learning.

\section{Pendahuluan}

Pendidikan adalah upaya sadar dan terencana manusia dalam memahami diri sendiri dan lingkungannya serta untuk mendapatkan perubahan dalam dirinya. Wawasan dan pengetahuan yang didapat merupakan salah satu bentuk produk dari proses pendidikan yang telah dilewati oleh siswa selama proses pembelajaran. Proses pembelajaran harus dirancang secara sistematis dengan memfokuskan perhatian pada siswa (Al Farizi, M. F., Sudiyanto, 2019, Zakirman, 2017) . Dalam membangun dan mendesain pembelajaran dibutuhkan kerjasama tim antara guru dan siswa untuk tercapainya tujuan pembelajaran yang diinginkan (Genty, 2013). Sekolah khususnya tercermin dalam proses pembelajaran, harus mampu merangsang kreativitas, rasa ingin tahu, dan rasa percaya

Copyright (C) Universitas Pendidikan Ganesha. All rights eserved.

${ }^{1}$ Corresponding author.

E-mail addresses: Ulhusna_82@yahoo.com(Mishbah Ulhusna1),Chidiana14@gmail.com(Sri Diana Putri²),

Zakirman1991@student.unp.ac.id (Zakirman) ${ }^{3}$ 
diri siswa, keinginan mereka untuk mengeksplorasi ide-ide serta mampu menyelesaikan masalah. Setiap siswa harus memiliki kesempatan untuk mengambil inisiatif, tanggung jawab, mengembangkan kemampuan mereka untuk bekerja secara mandiri dan bersama-sama dengan orang lain (Palmer \& Johansson, 2018).

Dewasa ini, keterampilan seperti membaca, menulis dan berhitung bukan satu-satunya keterampilan yang harus dimiliki siswa. Seiring berkembangnya zaman, keterampilan yang dibutuhkan mengalami perkembangan pula. Keterampilan yang dimaksud diantaranya adalah kreativitas, kemampuan berpikir kritis, berkomunikasi, dan berkolaborasi (Puspitasari, 2018). Kolaborasi adalah keterampilan abad ke-21 yang penting untuk kesuksesan akademik dan karier siswa (Jiangang Hao, Lei Chen, Michael Flor, 2017; Tracy \& Xu, 2018). Kolaborasi dapat didefinisikan sebagai kemitraan antara dua atau lebih siswa, yang berbagi tanggung jawab, akuntabilitas, dan peran untuk mencapai pemahaman bersama tentang masalah dan solusinya(Alexandra \& Barton, 2017;Davis \& Bos, 2018).

Keterampilan komunikasi dan kolaborasi dapat dipelajari melalui beberapa metode, tetapi cara yang paling baik adalah dengan berkolaborasi dan berkomunikasi secara langsung dengan orang lain. Collaboration skill sangat penting dalam kegiatan dikelas karena dapat menambah pengetahuan siswa dalam mencapai tujuan belajar. Kelompok siswa yang bekerja secara berkolaborasi akan menghasilkan lebih banyak pengetahuan. Penerapan collaboration skill pada siswa sekolah dasar dapat dilakukan dengan menerapkan pembelajaran yang dapat membuat siswa belajar untuk membagi tugas dengan adil, memotivasi anggota untuk bertanggungjawab atas tugasnya, dan menggunakan kemampuan sosial dengan baik (Puspitasari, 2018).

Penelitian menunjukkan bahwa kolaborasi memiliki efek yang berpengaruh pada pembelajaran siswa dan retensi pengetahuan. Keunggulan pembelajaran dengan tujuan akhir kolaborasi adalah: melatih pembagian kerja yang efektif; meningkatkan karakter tanggung jawab siswa, penggabungan informasi dari berbagai sumber pengetahuan, perspektif, pengalaman; dan peningkatan kreativitas dan kualitas solusi yang dirangsang oleh gagasan anggota dalam setiap kelompok(Child, 2016;Dooley \& Sexton-Finck, 2017) . Pembelajaran kolaboratif telah menjadi praktik pengajaran yang diterima secara luas selama beberapa dekade dalam pendidikan profesional(Ying-Hsui Liu \& LaShaune, 2017). Pembelajaran dengan tujuan akhir untuk peningkatan keterampilan kolaborasi siswa dapat dirancang pada setiap pokok pembelajaran. Salah satu pembelajaran yang relevan dengan keterampilan kolaborasi adalah matematika. Matematika adalah ilmu tentang struktur, keteraturan, dan hubungan yang telah berevolusi dari penghitungan, pengukuran, dan menggambarkan bentuk objek. Ini berkaitan dengan penalaran logis dan perhitungan kuantitatif. Setiap orang menggunakan matematika untuk menyelesaikan masalah yang terlihat dalam kehidupan sehari-hari(Esra, 2018). Penguasaan konsep matematika secara individu penting untuk mengembangkan kompetensi dan hasil belajar matematika (Suciati, B., \& Sugiman, 2019). Hasil belajar meliputi pengetahuan siswa, sikap dan keterampilan.

Masalahnya yang terjadi adalah adanya kesenjangan antara harapan dan kenyataan dimana hasi observasi menemukan bahwa keterampilan kolaboration siswa rendah dan secara tidak langsung mempengaruhi hasil belajar matematika. Berdasarkan hasil pengamatan secara langsung di kelas III SDN 19 Nan Sabaris, siswa masih sulit untuk berkolaborasi dalam pembelajaran. Jika kegiatan pembelajaran dilakukan secara berkelompok siswa lebih banyak menghabiskan waktunya untuk bercerita dan tidak menyelesaikan tugas yang diberikan oleh guru. Kerja kelompok biasanya hanya dikerjakan oleh satu atau dua siswa saja dan kebanyakan siswa tidak mengerti apa yang harus dikerjakan. Sedangkan dari hasil pembelajaran kelompok terlihat masih banyak siswa yang belum mencapai skor diatas KKM (hanya 40\%). Berdasarkan hal ini terlihat bahwa keterampilan kolaborasi siswa masih rendah. Penyebabnya adalah kecemasan siswa terhadap matematika dan kesiapan guru dalam mendesain dan merancang pembelajaran yang sesuai dengan tumbuh kembang siswa. Kecemasan terhadap matematika adalah masalah yang signifikan di sekolah, universitas dan lembaga pendidikan lainnya. Salah satu faktor terbesar dalam keberhasilan pendidikan matematika adalah bagaimana perasaan siswa. Ketika siswa santai dan nyaman, keberhasilan tampaknya datang secara alami, tetapi ketika siswa merasa stres, tergesa-gesa atau cemas, hasilnya sangat berbeda (Theodosia \& Nick Frederiksen, 2018) .Atas dasar ini perlu diciptakan konsep pembelajaran yang dapat memberikan kesempatan kepada siswa agar merasa nyaman dalam pembelajaran matematika, santai dan dapat berhasil mencapai tujuan pembelajaran. Selain kecemasan dan stres yang berkembang dalam diri siswa terhadap matematika, faktor lain yang ikut mempengaruhi keberhasilan pembelajaran adalah kesiapan guru dalam mendesain pembelajaran. Studi mengidentifikasi kesiapan guru sebagai dimensi penting yang dapat membantu meningkatkan kinerja siswa dalam Matematika (Kariuki, L. W., Njoka, J. N. and Mbugua, 2019). Guru perlu 
mendesain pembelajaran dan menggunakan media yang tepat dalam mengajarkan matematika di kelas khususnya di sekolah dasar.

Belajar melalui media ini memungkinkan siswa untuk lebih kuat dalam segi pemahaman, menciptakan rasa nyaman dan menyenangkan dalam mengikuti porses pembelajaran (Robbins, S., Gilbert, K., Chumney, F., \& Green, 2019;Emanuela \& Valente, 2015). Media merupakan alat bantu dan perantara guru dalam menyampaikan atau memberikan latihan kepada siswa (Michael, 2015;Selantik-Ay \& Duban, 2018;Zakirman, Z., \& Hidayati, 2017). Hubungan anak dengan media sebenarnya telah dimulai dimulai sejak bayi. Saat ini, media pembelajaran anak-anak terangkum dalam berbagai jenis diantaranya, termasuk Internet, koran, permainan, ponsel, majalah, dan pesan teks. Sekitar setengah dari anak-anak dalam kelompok usia 6-10 (usia sekolah) menggunakan media seperti Internet antara tiga sampai sepuluh jam seminggu. Tujuan dari anak-anak ini adalah untuk bermain game (Arslan-Cansever, 2019). Game merupakan sesuatu yang popular bagi anak, dan tidak tertutup kemungkinan game dapat diintegrasikan dalam proses pembelajaran anak agar tercapai tujuan belajar yang maksimal(Jennifer \& Cathrin, 2012) .

Permainan dan anak-anak (rentang usia sekolah dasar) merupakan sesuatu yang tidak dapat dipisahkan (Z. Zakirman, 2019). Karakteristik siswa sekolah dasar selalu diidentikkan dengan bermain. Bermain dan anak merupakan satu kesatuan yang tidak dapat dipisahkan. Aktivitas bermain dilakukan anak dan aktivitas anak selalu menunjukkan kegiatan bermain (Nur Azmi, Yusman, \& Nurhasanah, 2017). Anak-anak belajar dengan baik melalui permainan. Melalui permainan, semua bidang perkembangan anak dapat ditingkatkan. Permainan didefinisikan sebagai aktivitas menyenangkan dan memainkan peran penting dalam perolehan keterampilan baru anakanak. Menyadari pentingnya hal ini, pendidik menggunakan permainan sebagai alat yang paling penting dalam perencanaan dan pengelolaan proses pendidikan anak. Ada beberapa pendekatan untuk pembelajaran berbasis permainan, diantaranya: 1) Permainan Edukasi: Permainan ini termasuk permainan yang dirancang untuk mencapai tujuan pembelajaran dan membantu peserta didik mendapatkan pengetahuan dan keterampilan yang ditargetkan. 2) Permainan Hiburan: Awalnya tidak dimaksudkan untuk tujuan pendidikan tetapi kemudian disesuaikan dengan lingkungan pendidikan karena efek motivasi mereka. 3) Permainan berbasis masalah: memaksa peserta didik untuk menyelesaikan masalah dan berpikir dengan cara yang berbeda dalam konten pembelajaran yang direncanakan dan tidak direncanakan untuk tujuan permainan. 4) Gamifikasi: Ini mengacu pada penggunaan mekanika game (seperti hadiah, skor, lencana, dan tabel pemimpin) dalam konten non-game untuk menarik pelajar, memotivasi kegiatan, meningkatkan pembelajaran, dan menyelesaikan masalah (Halil, 2019).

Beberapa manfaat dari permainan jika diintegrasikan dalam kegiatan pembelajaran anak: 1) Permainan meningkatkan kreativitas dan pemecahan masalah siswa. 2) Permainan berkontribusi pada pengembangan pengaturan diri dan keterampilan sosial seperti turn-taking, kolaborasi, mengikuti aturan, empati, dan motivasi (Polona \& Vlasta Hus, 2018). Pada umumnya, permainan merupakan sesuatu yang familiar dan sesuai dengan hobi peserta didik sehingga dapat memicu rasa ingin tahu peserta didik. Dengan adanya permainan dalam pembelajaran, diharapkan agar peserta didik dapat berpartisipasi aktif dalam proses pembelajaran sehingga dapat meningkatkan penguasaan materi dan menumbuhkan minat belajar peserta didik. Salah satu permainan yang akan dikembangkan sebagai media pembelajaran adalah permainan ludo. Permainan ini dimodifikasi dengan kartu-kartu soal yang berisi pertanyaan-pertanyaan tentang materi. Permainan ludo dipilih karena permainan ini merupakan salah satu permainan yang menyenangkan, menghibur, dan mudah dilakukan oleh peserta didik (Mufida \& Yusman Wiyatmo, 2018). Bermain merupakan suatu kegiatan tanpa adanya unsur paksaan, memberikan anak kegembiraan, harapan serta kebebasan dan keterampilan anak agar dapat mengekspresikan dirinya melalui bermain secara spontan sebagai alat bantu belajar dalam mengembangkan dirinya untuk mencapai berbagai kemampuan dan keterampilan tertentu pada anak. Teori-Teori yang mendasari permainan ludo diantaranya: 1) Teori Memori, memori adalah tempat penyimpanan informasi setiap kejadian dalam kehidupan dan sebagai tempat pemrosesan informasi. 2) Law of Readiness, pemain dalam permainan ludo dipersiapkan untuk bermain dengan mengetahui peraturan permainan dan kegunaan dari permainan tersebut sehingga mereka merasa senang dan siap dalam bermain ludo. Permainan ludo memiliki banyak keunggulan dibandingkan jenis permainan lainnya, salah satunya adalah dapat meningkatkan kerjasama siswa dan meningkatkan keterampilan kolaborasi siswa (Iriani \& Dewi Retno, 2010). Oleh karena itu agar siswa dapat berkolaborasi dengan baik maka digunakan model pembelajaran yang menggunakan media pembelajaran permainan ludo.

Berdasarkan paparan tersebut tujuan dari penelitian ini adalah untuk menggali penggunaan permainan ludo terhadap keterampilan kolaborasi siswa pada mata pelajaran matematika. 
Penelitian ini hanya meneliti tentang dampak permainan ludo terhadap keterampilan kolaborasi siswa yang akan dibelajarakan matematika.

\section{Metode}

Jenis penelitian yang dilakukan adalah ekspererimen semu, dimana penelitian ini akan mengukur dua variable yaitu variable bebas pemberian permainan Ludo dalam pembelajaran sedangkan variable terikatnya yaitu keterampilan kolaborasi siswa yang mengikuti pelajaran. Teknik sampling yang digunakan adalah purposive sampling dengan total siswa sebagai sampel sebanyak 21 orang. Instrument pengumpulan data yang digunakan dalam penelitian adalah lembar penilaian keterampilan kolaborasi siswa. Lembar keterampilan kolaborasi siswa di ukur dengan indicator 15 indikator kolaborasi (Robbins, S., Gilbert, K., Chumney, F., \& Green, 2019), yaitu: 1) Bekerja secara produktif bersama teman sekelompok; 2) Berpartisipasi dan berkontribusi secara aktif; 3) Seimbang dalam mendengar dan berbicara, menjadi yang utama dan menjadi pengikut dalam kelompok; 4) Menunjukkan fleksibilitas dan berkompromi; 5) Bekerja secara kolega dengan berbagai tipe orang; 6) Menghormati ide-ide orang lain; 7) Menunjukkan keterampilan pengambilan suatu pandangan atau perspektif; 8) Menghargai kontribusi masing-masing anggota kelompok; 9) Mencocokkan tugas dan pekerjaan berdasarkan kekuatan dan kemampuan individu anggota kelompok; 10) Bekerja dengan orang lain untuk membuat keputusan yang mencakup pandangan beberapa individu; 11) Berpartisipasi secara hormat dalam diskusi, debat, dan perbedaan pendapat; 12) Berkomitmen untuk mendahulukan tujuan kelompok; 13) Mempertimbangkan kepentingan dan kebutuhan kelompok yang lebih besar; 14) Bekerja sama untuk menyelesaikan masalah dan menghasilkan ideide dan produk baru; 15) Bertanggung jawab bersama untuk menyelesaikan pekerjaan. Setelah intrumen dibuat, untuk selanjutnya akan diuji validasi dan reliabilitas tes apakah lembar kolaborasi bisa digunanakan dan dapat membedakan antara siswa yang mempunyai keterampilan kolaborasi dan tidak selama proses pembelajaran. analisis data yang dilakukan adalah analisis infernsial, yang terdiri dari dua uji yaitu uji prasyarat dan uji hipotesis. Uji prasyarat yang dilakukan adalah uji normalitas dan uji homogenitas, dimana kedua uji ini bertujuan untuk mengetahuai apakah data hasil penelitian bersifat normal dan homogeny, yang nantinya akan digunakan untuk syarat uji hipotesis. Untuk pengujian hipotesis digunakan paired sample t-test dengan ketentuan Dengan ketentuan 1) tolak $\mathrm{H}_{\mathrm{o}}$ jika nilai sig. (2-tailed) lebih kecil dari nilai alfa (0.05), dan 2) terima $\mathrm{H}_{\mathrm{o}}$ jika nilai sig. (2tailed) lebih besar dari nilai alfa (0.05).

\section{Hasil dan Pembahasan}

Penelitian ini merupakan penelitian ekperimen semu, dengan mencari pengeruh penggunaan permainan ludo terhadap keterampilan kolaborasi siswa. Aspek kolaborasi siiswa diukur dengan 15 indikator yang digunakan untuk menagamati proses pembelajaran selama penelitian berlangsung. Analisis data dalam penelitian menggunakan uji paired sample t-test dengan sebelumnya melakukan uji prasyarat yaitu uji kenormalan dan uji homogenitas. Uji normalitas menggunakan uji kolmogorov-smirnov dan untuk pengujian homogenitas data menggunakan uji Levene. Hasil perhitungan untuk uji normalitas dan homogenitas data dapat dilihat pada Tabel 1.

Tabel 1. Hasil Uji Normalitas Data Penilaian Keterampilan Kolaborasi Siswa

\begin{tabular}{clcc}
\hline No & \multicolumn{1}{c}{ Variable } & Before & Value \\
& After \\
\hline 1 & Mean & 70.48 & 83.71 \\
2 & N & 21 & 21 \\
3 & Std. Deviation & 6.794 & 8.427 \\
4 & Kolmogoriv-Smirnov Z & 0.854 & 0.605 \\
5 & Sig. (2-tailed) & 0.459 & 0.857 \\
\hline
\end{tabular}

Data akan normal apabila nilai Sig. (2-tailed) lebih besar dari nilai alfa $(0,05)$. Berdasarkan hasil uji normalitas data penelitian, nilai Sig. (2-tailed) lebih besar dari nilai 0,05. dapat disimpulkan kelompok data penilaian keterampilan kolaborasi siswa antara sebelum dan sesudah penggunaan media ludo dalam pembelajaran matematika telah terdistribusi normal. 
Tabel 2. Hasil Uji Homogenitas Data Penilaian Keterampilan Kolaborasi Siswa

\begin{tabular}{clc}
\hline No & \multicolumn{1}{c}{ Variable } & Value \\
\hline 1 & Levene Statistic & 2.606 \\
2 & df1 & 1 \\
3 & df2 & 40 \\
4 & Sig. (2-tailed) & 0,114 \\
\hline
\end{tabular}

Data akan homogen apabila nilai Sig. (2-tailed) lebih besar dari nilai alfa (0.05). Berdasarkan hasil uji homogenitas data penelitian, nilai Sig. (2-tailed) lebih besar dari nilai 0,05. dapat disimpulkan kelompok data penilaian keterampilan kolaborasi siswa antara sebelum dan sesudah penggunaan media ludo dalam pembelajaran matematika telah homogen.

Tabel 3. Hasil Uji Paired Sample t-test Data Penilaian Keterampilan Kolaborasi Siswa

\begin{tabular}{llc}
\hline No & Variable & Value \\
\hline 1 & Mean & 75.59 \\
2 & Std. Deviation & 9.773 \\
3 & T & 50.128 \\
4 & Df & 41 \\
5 & Sig. (2-tailed) & 0.0000 \\
\hline
\end{tabular}

Dengan melihat data hasil analisis pada tabel 3, terlihat bahwa nilai sig. (2-tailed) sebesar 0.0000 lebih kecil dari nilai alfa (0.05). Sehingga dapat disimpulkan bahwa terdapat perbedaan keterampilan berkolaborasi siswa yang signifikan antara sebelum dan sesudah diberikan perlakuan yaitu meningkatnya keterampilan berkolaborasi siswa. Hal ini membuktikan bahwa penggunaan permainan ludo untuk meningkatkan keterampilan kolaborasi siswa dalam pembelajaran Matematika berhasil.

Ada banyak cara untuk memahami anak-anak, berkomunikasi dengan mereka, dan berbagi dunia mereka. Permainan mewujudkan motivasi internal yang sangat penting untuk belajar dan bekerja. Pada saat yang sama, bermain sangat penting untuk perkembangan anak dan mencerminkan perkembangan anak. Ini adalah kebutuhan vital untuk bermain, nutrisi dan merupakan nutrisi untuk perkembangan dan pendidikan anak yang sehat dalam arah fisik dan mental.

Bermain menempati tempat penting dalam kehidupan anak-anak dan sangat penting untuk belajar. Menurut Froebel, anak itu belajar dan mau belajar selama bermain. Anak itu mendapatkan kelegaan emosional dengan bertindak secara mandiri dalam dunia bebasnya sendiri yang imperatif. Selain itu, anak belajar dan menerapkan banyak aspek hidup bersama, seperti berteman melalui permainan, memahami peran, menghormati hak dan kebebasan, berbagi, menang, kalah, dan berkolaborasi(Dursun \& Olcay Ozsoy, 2018).

Dalam melaksanakan permainan, ada sesuatu yang menyenangkan, betapapun seriusnya, yang melibatkan persaingan untuk mencapai tujuan tertentu dan mematuhi aturan. Permainan membutuhkan strategi, taktik, dan inisiatif dari pemain (siswa). Karenanya, harus ada pemenang. Permainan sangat berharga untuk mendorong keterampilan sosial, keterampilan kolaborasi, merangsang diskusi, mengembangkan strategi untuk mempelajari konsep baru, memperkuat keterampilan dan konsep sebagai bantuan untuk simbolisasi dan logika, dan untuk membantu pengembangan pemahaman matematika. Permainan ludo dalam pembelajaran matematika membantu siswa untuk mengeksplorasi konsep bilangan dasar seperti urutan dan seri penghitungan, angka dan angka serta operasi bilangan dasar. Melibatkan permainan dalam pembelajaran matematika membantu siswa untuk memperdalam pemahaman dan penalaran. Guru harus sering memberikan kesempatan bagi siswa untuk mengikuti permainan, dan kemudian membimbing siswa berkolaborasi, mengemukakan ide-ide matematika yang muncul ketika siswa menemukan pola, hubungan, dan strategi baru.

Kekuatan terbesar permainan dalam pengajaran dan pembelajaran matematika adalah kemampuan permainan untuk menyediakan latihan dan aplikasi praktis. Dengan demikian, siswa belajar dan menyempurnakan keterampilan matematika mereka dengan cara bermain. Ludo merupakan salah satu contoh permainan matematika yang paling direkomendasikan untuk meningkatkan pengetahuan dan keterampilan kolaborasi siswa. Dalam permainan ludo, setiap siswa akan berpartisipasi aktif, ikut memikirkan strategi untuk mencapai kemenangan tim dan lebih 
mengedepankan berkolaborasi dengan anggota tim melawan tim dalam kelompok lain. Nilai-nilai edukasi yang tercermin dalam permainan ludo diantaranya: 1) Ludo memberikan kesenangan dan pada saat yang sama, merangsang pemikiran matematika. 2) Ludo menghadirkan peluang untuk latihan, guru kemudian dapat mengamati atau menilai siswa dan bekerja dengan kelompok. 3) Ludo dapat memperkuat apa yang telah diajarkan di kelas. 4) Faktor pendorong terutama bagi siswa yang lambat, siswa di bawah rata-rata dan dyscalculics. Dyscalculia adalah gangguan kemampuan untuk memecahkan masalah matematika, biasanya akibat disfungsi otak. Ludo hadir untuk mengatasi masalah tersebut. 5) Untuk meningkatkan skill kolaborasi siswa dan menciptakan pembelajaran berbasis tantangan (Nekang, 2018).

Ludo berpotensi sebagai permainan untuk mempromosikan keterlibatan siswa, meningkatkan minat serta menciptakan rasa saling membutuhkan dan kolaborasi dalam setiap kelompok (Southgate, E., Budd, J., \& Smith, 2017). Bermain tidak diragukan lagi merupakan skenario ideal bagi anak untuk memperoleh pembelajaran dalam berbagai cara (Del Moral \& Fernandez, 2018). Bermain telah terbukti memberikan lingkungan yang kuat untuk belajar dan mereka memotivasi anak-anak untuk belajar bahkan mereka yang pada awalnya tidak tertarik pada materi pelajaran atau menganggap konten sebagai yang paling sulit dipahami. Permainan juga dapat membantu anak-anak meningkatkan keterampilan berpikir, kolaborasi pemecahan masalah mereka, dan keterampilan spasial persepsi dan visualisasi (Zitto \& Joel Mtebe, 2018)(Zitto \& Joel, 2018). Hasil penelitian lainnya tentang ludo menunjukkan bahwa permainan ludo efisien dalam mengembangkan keterampilan matematika siswa (Baranyai, T., Egri E., Molnár, 2019) . Saat berpartisipasi dalam permainan siswa mendapatkan peluang untuk meningkatkan karakteristik fisik, emosi, dan sosial (Meryem, 2019). Beberapa pengajar matematika telah menyelidiki cara-cara di mana kegiatan pembelajaran bagi siswa yang sangat populer saat ini adalah membawa permainan ke kelas matematika untuk menangkap minat siswa dan memfasilitasi pembelajaran mereka (Maria \& Theodosia, n.d.). Beberapa keterbatasan permainan ludo dalam pembelajaran diantaranya diperlukan manajemen waktu dan perencanaan waktu yang matang agar waktu yang tersedia dapat dioptimalkan dalam pembelajaran.

\section{Simpulan}

Tujuan dari penelitian ini adalah untuk melihat pengaruh penggunaan media ludo dalam meningkatkan keterampilan kolaborasi siswa pada pembelajaran matematika di SD. Berdasarkan hasil analisis data dapat disimpulkan bahwa terdapat perbedaan keterampilan kolaborasi yang signifikan antara siswa yang belajar dengan menggunakan media ludo dan belajar secara konvensional. Belajar matematika menggunakan media ludo terbukti dapat melibatkan keseluruhan siswa aktif untuk belajar karena media yang dikembangkan sesuai dengan kebutuhan belajar siswa pada tingkat SD. Media ludo juga dapat meningkatkan kerjasama, rasa saling ketergantungan antara masing-masing siswa dalam mendapatkan pengetahuan baru dan memotivasi siwa agar dapat meningkatkan pengetahuan lebih lanjut. Pada masa yang akan datang diharapkan media ludo tidak hanya dapat dikembangkan pada materi matematika, tetapi dapat diperluas pada materi IPA, IPS dan bahasa. Kekreatifan guru dalam mendesain pembelajaran sangat dibutuhkan agar suksesnya pembelajaran dengan bantuan media ludo.

\section{Daftar Rujukan}

Al Farizi, M. F., Sudiyanto, \& H. (2019). Analysis of Indonesian language learning obstacles in primary schoolsJennifer, G., \& Cathrin, H. (2016). Console Game-Based Pedagogy: A Study of Primary and Secondary Classroom Learning through Console Video Games. International Journal of Game-Based Lear. International Journal of Educational Methodology, 5(4), 663669. https://doi.org/https://doi.org/10.12973/ijem.5.4.663

Alexandra, D. F., \& Barton, S. M. (2017). Collaboration of General and Special Education Teachers: Perspectives and Strategies. Intervention in School and Clinic, 1-8. https://doi.org/ $10.1177 / 1053451217693370$

Arslan-Cansever, B. (2019). Investigation of third grade students' views on media literacy. Investigation of Third Grade Students' Views on Media Literacy, 5(1), 265-373.

Baranyai, T., Egri E., Molnár, A. É. . \& Z.-M. I. (2019). Developing Preservice Primary School Teachers' Mental Computation Competency by Games. Acta Didactica Napocensia, 12(1), 153-164. 
Child, S. (2016). Collaboration In The 21st Century: Implications For Assessment. Research Matters: A Cambridge Assessment publication. Research Matters: A Cambridge Assessment Publication, 22, 17-22.

Davis, K., \& Bos, J. (2018). Playing in the Virtual Sandbox: Students' Collaborative Practices in Minecraft. International Journal of Game-Based Learning, 8(3), 56-76. https:// doi.org/10.4018/IJGBL.2018070104

Del Moral, M. ., \& Fernandez. (2018). Game-Based Learning: Increasing the Logical-Mathematical, Naturalistic, and Linguistic Learning Levels of Primary School Students. Journal of New Approaches in Educational Research, 7(1), 31-39. https://doi.org/ 10.7821/naer.2018.1.248

Dooley, K., \& Sexton-Finck, L. (2017). A focus on collaboration: Fostering Australian screen production students' teamwork skills. Journal of Teaching and Learning for Graduate Employability, 8(1), 74-105.

Dursun, G., \& Olcay Ozsoy. (2018). The Preschool And Primary School Educational Games: A Teachers' Perspective. European Journal of Education Studies, 4(5), 26-34.

Emanuela, M., \& Valente, A. (2015). Learning via Game Design: From Digital to Card Games and Back Again. The Electronic Journal of E-Learning, 13(3), 167-180.

Esra, A. (2018). Perceptions And Opinions Of Students Studying At Primary School Mathematics Teaching Department About The Concept Of Mathematics. Educational Research and Reviews, 13(7), 260-269. https://doi.org/10.5897/ERR2018.3514

Genty, R. (2013). Collaboration Skills Pre-Service Teachers Acquire In A Responsive Preparation Program. Journal of Instructional Pedagogies, 1-9.

Halil, K. (2019). On primary school teachers' training needs in relation to game-based learning. International Journal of Curriculum and Instruction, 11(2), 285-296.

Iriani, H., \& Dewi Retno. (2010). Efektifitas Ludo Words Game (LWG) terhadap Peningkatan Kosakata Bahasa Inggris pada Anak Studi Kasus Pada Siswa Kelas IV SD Muhammadiyah 4 Pucang. Jurnal Psikologi UNAIR, 2(2), 1-10.

Jennifer, G., \& Cathrin, H. (2012). Console Game-Based Pedagogy: A Study of Primary and Secondary Classroom Learning through Console Video Games. International Journal of Game-Based Learning, 2(2), 35-54. https://doi.org/10.4018/ijgbl.2012040103

Kariuki, L. W., Njoka, J. N. and Mbugua, Z. K. (2019). Influence of Teachers Preparedness on Performance of Pupils in Mathematics in Lower Primary Schools in Aberdares Region of Kenya. European Journal of STEM Education, 4(1).

Maria, M.-M., \& Theodosia, P. (n.d.). Pre-Service Teacher Training on Game-Enhanced Mathematics Teaching and Learning. Tech Know Learn, Springer Science+Business Media Dordrecht. https://doi.org/10.1007/s10758-016-9275-y.

Meryem, A. (2019). The Effects of Mind Games and Games Containing Physical Activity on Attention and Visual Perception Levels of Primary School Students. Journal of Education and Learning, 8(6), 72-82.

Michael, D. (2015). The building blocks of digital media literacy: socio- material participation and the production of media knowledge. Journal of Curriculum Studies, 47(3), 416-439. https://doi.org/10.1080/00220272.2014.966152

Mufida, M., \& Yusman Wiyatmo. (2018). Pengembangan Media Pembelajaran Permainan Ludo Untuk Meningkatkan Enguasaan Materi Dan Minat Belajar Fisika Peserta Didik SMA. Jurnal Pendidikan Fisika, 240-249.

Nekang, F. (2018). The Use of Mathematical Games and Secondary School Students'Achievement in Mathematics in Fako Division, South West Region of Cameroon. Journal of Education \& Entrepreneurship, 5(1), 21-32. Retrieved from https://doi.org/10.26762/jee. 2018.40000009

Nur Azmi, M., Yusman, A. R. A., \& Nurhasanah. (2017). Jelajah Sejarah Melalui Ludo Carpet: Upaya Mewujudkan Generasi Nasionalis Bagi Anak Sekolah Dasar. Jurnal Penelitian Pendidikan 
INSANI, 20(2), 122-126.

Palmer, H., \& Johansson, M. (2018). Combining entrepreneurship and mathematics in primary school - what happens? Education Inquiry. https://doi.org/10.1080/20004508.2018.1461497

Polona, J., \& Vlasta Hus. (2018). Teaching Social Studies With Games. International Journal of GameBased Learning, 8(2), 68-79. https://doi.org/10.4018/IJGBL.2018040106

Puspitasari, N. (2018). Peningkatan Collaboration Skill Siswa sebagai Kecakapan Abad 21 Melalui Pembelajaran Model Cooperative Learning Tipe Team Accelerated Instruction (Tai) Mata Pelajaran Ipa Di Sd Negeri Kotagede 1. Jurnal Pendidikan Guru Sekolah Dasar, 38(7), 27673780 .

Robbins, S., Gilbert, K., Chumney, F., \& Green, K. (2019). The Effects of Immersive Simulation on Targeted Collaboration Skills among Undergraduates in Special Education. Teaching \& Learning Inquiry, 7(2). https://doi.org/http://dx.doi.org/10.20343/teachlearninqu.7.2.11

Selantik-Ay, T., \& Duban, N. (2018). Media literacy from the eyes of children: an interdisciplinary approach. Cypriot Journal of Educational Science, 13(3), 372-387.

Southgate, E., Budd, J., \& Smith, S. (2017). Press Play for Learning: A Framework to Guide Serious Computer Game Use in the Classroom. Australian Journal of Teacher Education, 42(7).

Suciati, K., B., M., \& Sugiman. (2019). The Single-Case Research of Coastal Contextual Learning Media on the Understanding of Numbers Counting Operation Concept. International Journal of Instruction, 12(3), 681-698. https://doi.org/ttps://doi.org/10.29333/iji.2019.12341a

Theodosia, P., \& Nick Frederiksen. (2018). The Effects of Mathematics Anxiety on Primary Students. Proceedings of the 41st annual conference of the Mathematics Education Research Group of Australasia). MERGA: Auckland.

Tracy, G. S., \& Xu, Y. (2018). Scaffolded Academic conversations: Access to 21st-Century Collaboration and Communication Skills. Intervention in School and Clinic, 1-9. https://doi.org/10.1177/ 1053451218762478

Ying-Hsui Liu, K. K., \& LaShaune, J. P. (2017). Exploration of Factors in the Early Collaboration Phase Affecting Virtual Groups' Overall Collaborative Learning Experiences. Journal of Educational Computing Research, O(0), 1-28. https://doi.org/10.1177/0735633117 715034

Zakirman, Z., \& Hidayati, H. (2017). Praktikalitas Media Video dan Animasi dalam Pembelajaran Fisika di SMP. Jurnal Ilmiah Pendidikan Fisika Al-Biruni, 6(1), 85-93.

Zakirman, Z. (2019). Peningkatan Minat Baca Siswa Melalui Penerapan Model Pembelajaran PlayThink-Pair-Share Di SDN 19 Nan Sabaris. Shaut Al-Maktabah: Jurnal Perpustakaan, Arsip Dan Dokumentasi, 11(1), 41-51.

Zakirman, Z. . (2017). Pengelompokkan Gaya Belajar Mahasiswa Menurut Teori Honey Mumford Berdasarkan Intensitas Kunjungan Pustaka. Jurnal Bimbingan Dan Konseling, 2(2).

Zitto, G., \& Joel Mtebe. (2018). Redesigning Local Games To Stimulate Pupils' Interest In Learning Numeracy In Tanzania. International Journal of Education and Development Using Information and Communication Technology, 14(3), 17-37. 